\title{
Bilateral Bundle Branch Block Due to Cardiac Metastasis of Pulmonary Carcinoma
}

\author{
Kohji Tamura, M.D., Masao Oguro, M.D., Yohji Aoki, M.D., \\ Akihiko Kawabe, M.D., Tadashi Mashima, M.D., \\ and Chutaro Oguro, M.D.
}

$\mathrm{M}$

ETASTATIC neoplasms may invade any part of the heart including occasionally the conductive system. The primary neoplasm may be situated at any site, although most of the tumors have their primary origin in the thoracic cage. ${ }^{8), 11)}$ Most cardiac tumors produce no clinical symptoms and ware discovered only at the postmortem examination. Occasionally, however, secondary tumors give rise to distinctive clinical features in the absence of usual other apparent causes.

Bilateral bundle branch block itself is only rarely seen and no such case caused by the cardiac involvement of the tumor has been reported yet as far as we know. In this report such a case is presented with definitive pathological findings and its etiologies are discussed.

\section{Ciase Report}

The patient was 67-year-old male who was referred to this hospital on Oct. 19, 1951, because of headache, cough, pale yellowish sputum and increasing pain in the right side of the chest for one month. The abnormalities of the chest X-ray were detected 6 days prior to the admission.

Family history and past history: Non-contributory.

Physical examination on admission revealed a moderately nourished and developed conscious male in no acute distress. Eyes: Cataracta incipiens and normal eye fundi. Neck: Normal. Chest wall: A hard mass of 3 by $1 \mathrm{~cm}$. in size was palpable which was firmly fixed to the chest wall in the right mamilla area. Cardiovascular system: The pulse was 78 and regular, and the blood pressure $140 / 80 \mathrm{~mm}$. Hg. The cardiac dullness was within normal limits and cardiac sounds were pure and faint. Chest: A few bubbling rales were audible at both upper lung fields and the crepitant rales over the right lower lung area. Lymphadenopathy: One lymph node of 1 by $1 \mathrm{~cm}$. in size was palpable without tenderness in the right inguinal area. Otherwise negative.

From the First Department of Internal Medicine (Director: Professor Mitsuo Nishikawa, M.D.), Niigata University School of Medicine, Niigata. 
Laboratory findings: On admission WBG 11,200 with differential, N. 82, Bands 3, E. 5, Mo. 2.5, L. 12; RBC $3.64 \times 10^{3}$, Hb. $84 \%$ (Sahli method); platelet 153,000 ; urinalysis: no sugar or protein; three positive urobilinogen; granular casts in the sediments; erythrocyte sedimentation rate was $108 \mathrm{~mm}$. in one hour; serum sodium $141 \mathrm{mEq} . / \mathrm{L}$; ; potassium $3.9 \mathrm{mEq} . / \mathrm{L}$; calcium $11.2 \mathrm{mg} . / 100 \mathrm{ml}$.; liver function tests, negative; cholesterol $178 \mathrm{mg} . / 100 \mathrm{ml}$; electrophoresis, total protein $5.2 \mathrm{mg} . / 100 \mathrm{ml}$. albumin $48.1 \%$, al pha-globulin $16.3 \%$, beta-globulin $14.8 \%$, gamma-globulin $20.8 \%$; cerebrospinal fluid, initial pressure $180 \mathrm{~mm} . \mathrm{H}_{2} \mathrm{O}$, cells $8 / 3$ of lymphocytes, protein $30 \mathrm{mg} / 100 \mathrm{ml}$. Cytological examinations of ascites: Normal pathology. Biopsy of the tumor in the chest wall: carcinoma simplex. The chest X-ray on admission showed an area of increased density of 4 by $5 \mathrm{~cm}$. in size at the right lower lung area spreading into the mediastinum. Electrocardiogram will be described later.

Hospital course and electrocardiographic interpretations: The patient was afebrile. The EGG on admission (Fig. 1) showed the pattern of left bundle branch block and sinus rhythm. A wide $R$ wave was seen in $V_{5-6}$. The QRS interval was $0.12 \mathrm{sec}$. and $\mathrm{q}$ wave was absent in these leads. The chest X-ray findings and the pathological examination on the biopsy specimen are considered compatible with the diagnosis of pulmonary carcinoma. Mitomycin was given 2 to $4 \mathrm{mg}$. daily for about one month.

On the 30th hospital day the pulse rate dropped suddenly to about $40 \mathrm{p} \mathrm{r}$ min. ECG at that time (Fig. 2) showed complete atrioventricular dissociation caused by bilateral bundle branch block. The ventricular pacing was

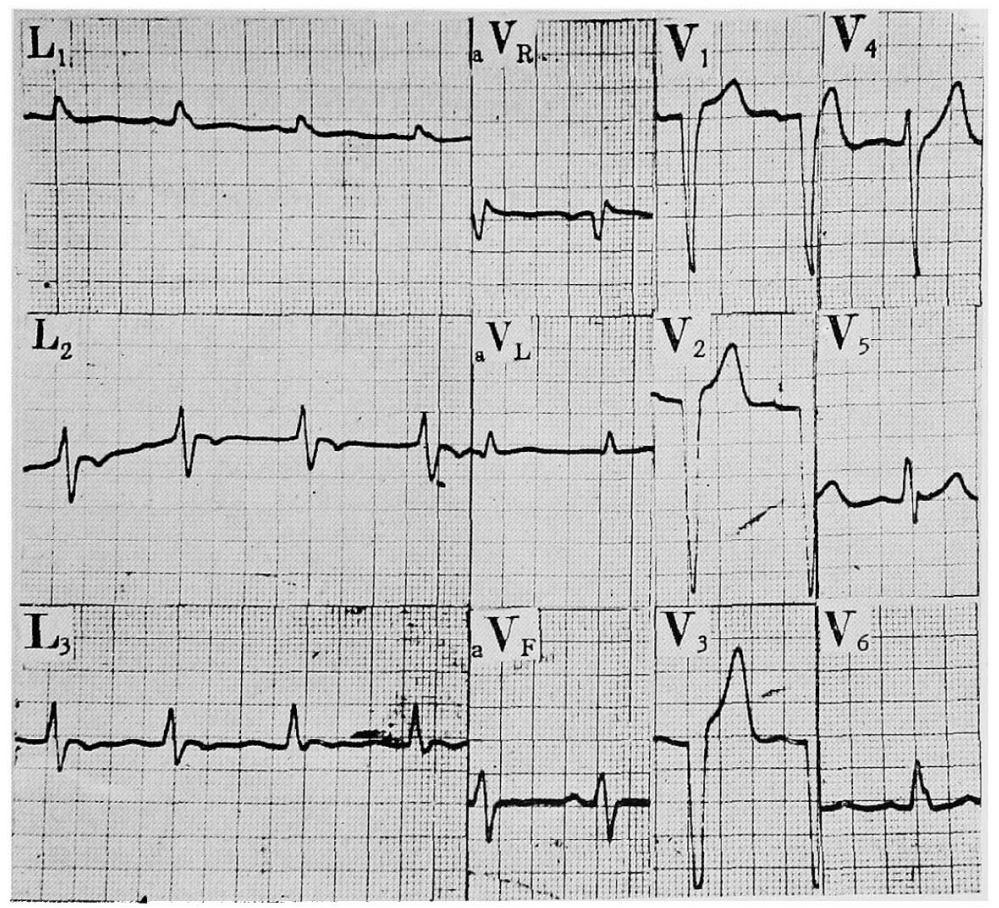

Fig. 1. ECG on admission. 


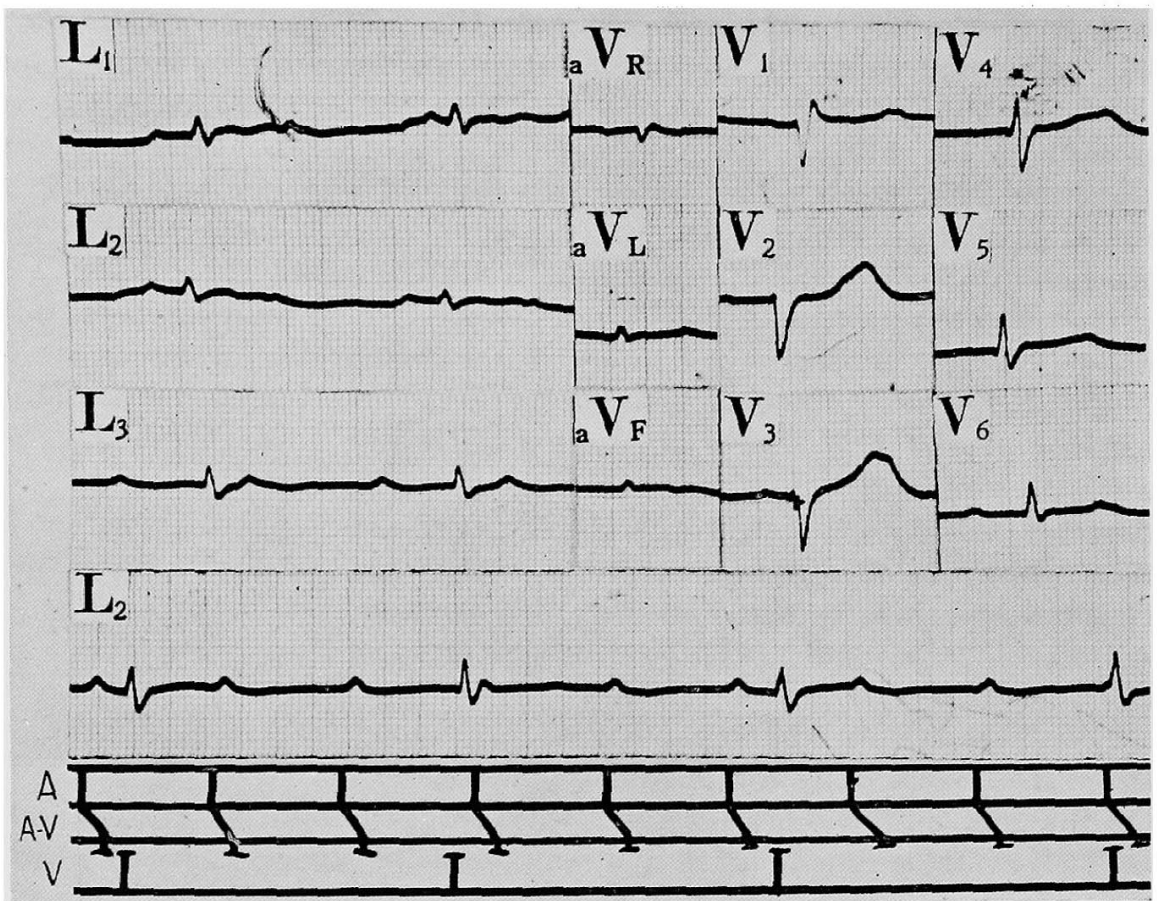

Fig. 2. EGG on the 30th hospital day showed complete atrioventricular dissociation.

regular and became slower. However lead $\mathrm{V}_{1}$ showed the pattern of the right epicardial complex, i.e. an $\mathrm{rSR}^{\prime}$ complex. The ventricular activation pattern was prolonged to $0.12 \mathrm{sec}$. Lead aVu recorded a left ventricular epicardial complex and resembled $\mathrm{V}_{6}$.

No other new symptoms and signs in the cardiovascular system developed. His general conditions, however, became poor. So the $\mathrm{Co}^{50}$ irradiation to the heart and the lung were abandoned. ECG remained essentially same throughout remainder of hospitalization. The patient expired on the $68 \mathrm{th}$ hospital day.

\section{Autopsy Findings}

Primary carcinoma was found in the right lower lobe of the lung. Microscopic examination revealed a carcinoma simplex and partially adenocarcinoma. The blood borne disseminations to tongue, testicles, thyroid, retroperitoneal lymph nodes, skin at the right mamilla area, liver, kidneys, stomach and heart were revealed. A whitish clouded pericardial effusion of about $100 \mathrm{ml}$. was found. The pericardium and the epicardium remained intact. The heart was enlarged and weighed $440 \mathrm{Gm}$. The coronary arteries were sclcrotic. Many gray hard, 1.0 by $1.0 \mathrm{~cm}$. in size, well demarcated, metastatic tumors were scattered in the myocardium involving also the upper part of the ventricular septum (Fig. 3).

Microscopic examination of that part revealed an intact sinus node. The atrioventricular node and the bundle of His were not positively identified but tumor invasion had stopped at the lure of the right and left bundles. Tumor 
cell infiltration was seen in both right and left branches of the bundle of His directly below the bifurcation. This had apparently produced a complete block in the conduction system at this level. Both ventricles were hypertrophic slightly. The metastatic tumor cells were seen in the papillary muscles. The endocardium and valves were normal except for a sclerotic mitral valve. The circumference of the slightly distended aorta was $8 \mathrm{~cm}$.

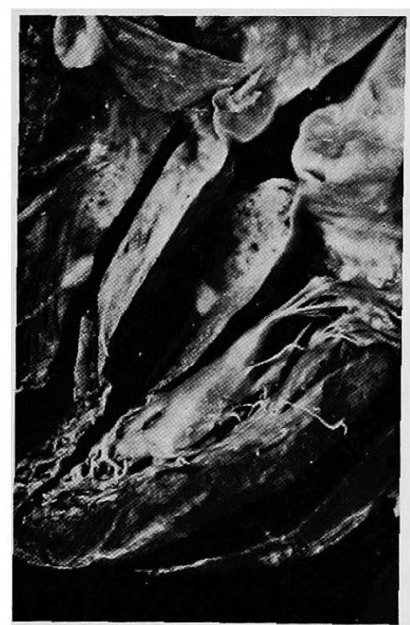

Fig. 3. The whitish shining part in center of the figure showed the metastatic involment of the septum macroscopically.

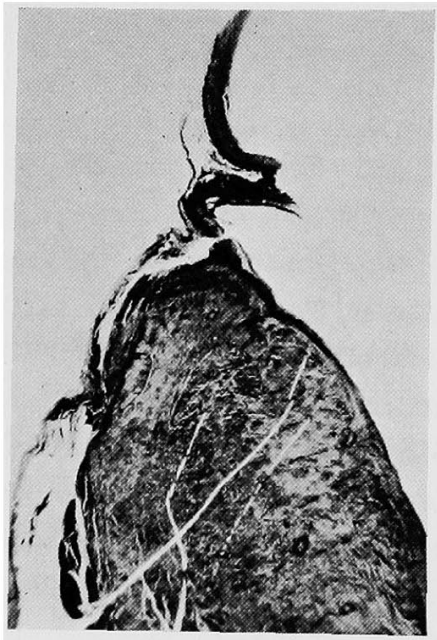

Fig. 4. Longitudinally cut surface of the upper part of the ventricular septum involving the right valve of the aorta. Tumor invaded the most part of the septum.

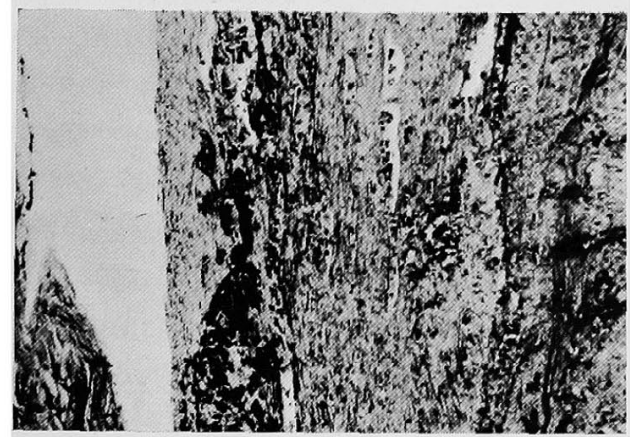

Fig. 5. Large magnification of left bundle. Tumor cells invaded almost to the endocardial wall and left bundle was affected.

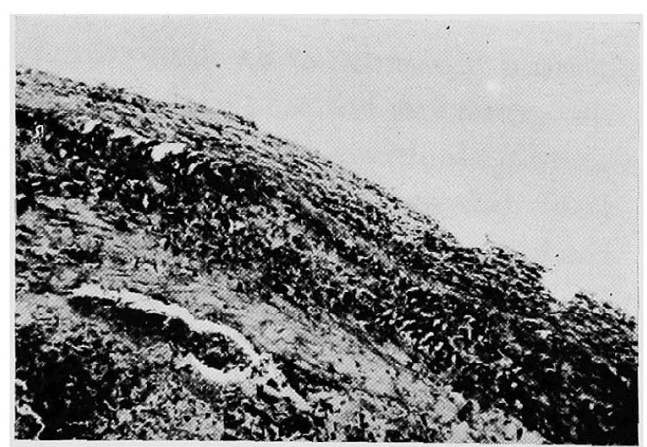

Fig. 6. Right bundle was also affected at the large magnification. 


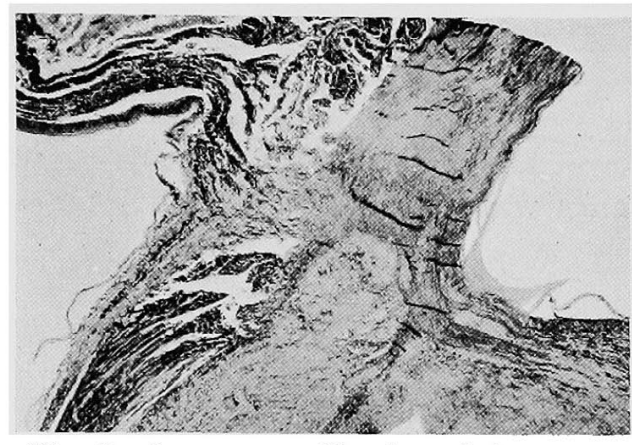

Fig. 7. Large magnification of the septum and whitish mass in the middle was tumor.

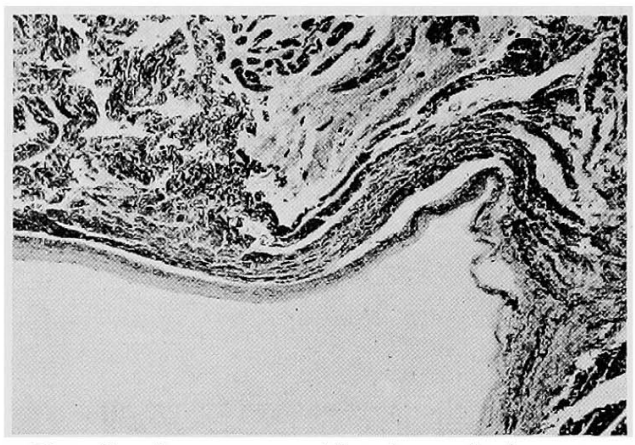

Fig. 8. Large magnification of the upper part of Fig. 7. This part was considered to be atrioventricular node and the common bundle of His, but tumor invasion was not revealed.

\section{Discussion}

It is reported that the ratio of the secondary tumor to the primary cardiac tumor is $20 \sim 40: 1.7)$ Secondary cardiac tumors are seen in $1.5 \%$ $\sim 13.9 \%^{8)}$ and $20.6 \%{ }^{9)}$ of all malignant tumors. Various authors have reported that 22 out of 105 cases, $^{6)} 16$ of 146 cases, $^{7)}$ and 21 of 93 cases $^{8)}$ of pulmonary carcinoma had shown the metastasis to the heart and pericardium. Hanfling 8 ) noted 6 cases of the myocardial involvement out of 21 cases of pulmonary carcinoma. The autopsy findings of 107 cases of all malignant tumors during past 10 years in our department ${ }^{11}$ ) revealed 17 cases of secondary cardiac involvement either microscopically and macroscopically. Two of them were caused by pulmonary carcinoma. The routes of metastasis to the heart are recognized as follows: ${ }^{8)}$ (a) The direct invasion to the myocardium through the pericardium. (b) The blood borne metastasis, namely tumor emboli. (c) The retrograde lymphatic metastasis through the tracheobronchial lymph nodes. The signs of the secondary cardiac tumor involvement of the myocardium are recognized as follows; atrial fibrillation and flutter, conductive disturbances, premature beats, persistent RS-T elevation, persistent T-wave inversion, low voltage, cardiac failure, coronary insufficiency, and so forth. Buckberg (1961) $)^{5)}$ reported 7 cases of complete atrioventricular block including his case. In his report he cited that about $20 \%$ of complete atrioventricular block diagnosed clinically were revealed to be bilateral bundle branch block. Bernstein ${ }^{4}$ also emphasized that many cases of complete atrioventricular block are due probably to bilateral bundle branch blozk rather than organic and functional lesions of the atrioventricular node of the bundle of His. Unfortunately the determination of bilateral bundle branch block clinically and pathologically is very difficult. Rosenbaum and Lepeschkin $(1955)^{1)}$ reported 9 cases of bilateral 
bundle branch block including his case in which the diagnosis were acceptable pathologically and clinically.

The mechanisms of bilateral bundle branch block are as follows: ${ }^{3)}$ (a) The sclerosis of the coronary arteries. The numbers of capillaries per square millimeter of the conductive system are half of those of the ventricles and so the conductive system is more liable to be anoxia. Also, the blood stream is more easily disturbed at the right bundle and the ascending part of the left bundle. (b) Endocarditis contributes to cause this disorder. (c) The metastatic cardiac tumor may be added to those mechanisms, though this mechanism has never been reported previously, as far as we know.

Vesell ${ }^{2}$ describsd 3 types of bilateral bundle branch block. First type: The pattern of right and left bundle branch block occur alternately or intermittently, in the same patient, together with changes in the P-R interval. The QRS configuration, however, appears to be affected only by the side which the blocking is greater. Second type: Initial ventricular activation occurs from right to left, terminal activation in the free right vintricular wall, and slight or greater prolongation of QRS. Third type: The electrocardiographic pattern consisted of the presence of a broad QRS with the intrincicoid deflection occurring late simultancously over the right and left precordium, but not in the intermediate area. There may be little or no increase in duration of the P-R interval.

This case belongs to the more advanced form of the first type, namely the complete blocking of both bundles. The electrocardiogram initially showed left bundle branch block but changed to a complete atrioventricular dissociation with a QRS pattern changed to the right bundle branch block.

So the seoffer two possible explanations: The first probability was that the carcinomatous infiltration caused the block of the left bundle at first and then the invasion spread to the atrioventricular node, and the fixed pacemaker occurred in the left ventricle. The second probability was that the left bundle was blocked initially by the tumor invasion, after which the fixed pacemaker in the left ventricle replaced the control of the heart. The second mechanism was confirmed pathologically.

To our regret, the patient was too poor to give the precordial $\mathrm{Co}^{60}$ irradiation, though this maneuver had been recognized to be specific therapy of this type of the disease. Recently one case of atrioventricular dissociation caused by cardiac reticulosarcoma was relieved temporarily by $\mathrm{Co}^{60}$ irradiation to the precordial area in our department. ${ }^{11}$ ) 


\section{SUMMARY}

Pathological examination of the conductive tissue of the heart has revealed that exact lodgement of the metastatic lesions. The pathogenesis of bilateral bundle branch block due to cardiac metastasis of pulmonary carcinoma has been presented with a brief presentation of the electrocardiographic pattern.

\section{AkNOWI EDGEMENT}

The pathological examinations were done by Hiroshi Kaneko, M.D. and authors are deeply indebted to his works and to the Department of Pathology, Niigata Universiry School of Medicine for their collaboration in this report.

\section{REFERENCES}

1. Rosenbaum, M.M. and Lepeschkin, E.: Am. Heart J. 50:38, 1955.

2. Vescll, H.: Am. Heart J. 63: 162, 1962.

3. Yater, W.M. et al.: Arch. Int. Med. 57 : 132, 1936.

4. Bernstein, W.M.: Am. J. Cardiol. 5: 799, 1960.

5. Buckberg, G.D.: Circulation 24:675, 1961.

6. Deloach, J.F.: Ann. Int. Med. 91: 224, 1953.

7. Prichard, R.W.: Arch. Path. 51: 98, 1951.

8. Hanfling, S.M.: Circulation 22: 474, 1960.

9. Cohen, G.U.: Ann. Int. Med. 42: 1238, 1955.

10. Shelburne, S.A.; Ann. Int. Med. 14: 728, 1940.

11. Tamura, K.: "Naika" (in Japanese, in print).

12. Basal, H.F. et al,: J.A.M.A. 22: 152, 1958. 